\title{
Soft tissue sore spots of an unknown origin
}

\section{Adam Meakins}

Trigger points are common clinical diagnoses in the musculoskeletal profession. However, questions have been raised about what they are and how they are treated. ${ }^{1}$ Trigger points were first described by Travell and Simons as tender, painful areas found in myofascial tissue when palpated. These are often described as muscle 'knots' or taut bands, and are considered to be areas of adverse sustained muscular contraction caused either from direct trauma to myofascial tissue or through repeated microtrauma from postural or activity-related stresses/ strains. This is believed to cause a crisis at the motor end plates, creating a sustained adverse muscular contraction that is then felt as pain either locally or referred elsewhere.

However, despite widespread acceptance of this theory, and a large and diverse industry built around the treatment of trigger points, including various deep tissue massage and acupressure techniques and more recently, the growing popularity of dry needling, the theory of adverse muscle knots and taut bands as a cause of soft tissue pain has never been adequately explained.

\section{SO WHAT ARE THEY?}

More and more clinicians question the accepted explanations for trigger points in the light of growing research and understanding in neurophysiology and pain science. It is questionable if trigger points are adverse areas of sustained contraction in muscles for a number of reasons and alternative causes of trigger points, such as peripheral neural inflammation or ischaemic tissues, may be more likely. ${ }^{2}$

The acceptance of knots in muscles never sat well with me. As a young physiotherapist, I regularly infuriated my educators as they attempted to teach me how to palpate trigger points, but despite provoking pain I could never feel anything adverse. Perhaps it was my lack of skill or experience in palpation; however, over a decade later, I can still confidently say that I have never felt a true trigger point.

When I discuss this with other therapists it seems that I am in a minority. Nearly all other therapists I speak to tell me that they have felt adverse knots from time to time, and they tell me I simply need more

Correspondence to Dr Adam Meakins, Department of Physiotherapy, Spire Bushey Hospital, Heathbourne Road, Bushey, Herts WD23 1RD, UK; adammeakins@hotmail.com training. Maybe they are right; maybe I just have sausage fingers that cannot palpate anything. However, there is evidence that even the world's leading experts are also unable to accurately or reliably locate trigger points. ${ }^{3}$ If these experts cannot find them, then what chance do the rest of us have?

\section{SO WHAT ABOUT THE EVIDENCE?}

Studies have tried to visualise trigger points using MR elastography, sonoelastography or Doppler ultrasound. However, these studies are of poor quality, lacking in control groups or descriptions of how they classified, diagnosed or located the trigger points. ${ }^{4}$

Tissue biochemistry research has been conducted around trigger points, and elevated levels of inflammatory and neurotransmitter chemicals have indeed been found. ${ }^{5}$ However, control tissue samples were similar.

Electromyography (EMG) studies have reported adverse electrical activity in and around trigger points. ${ }^{6}$ These very small elevated EMG spikes, however, cannot be reliably distinguished from background latent noise or artefacts from the fine, wire needles.

Dry needling for treatment of trigger points has scant evidence; studies have poor methods and high risk of bias. The proposed mechanism for dry needling is the needle point disrupts the motor end plate crisis by stimulating the neural tissue. However, demonstrated trigger points have not been shown to be adverse muscle contractions caused by motor end plates in crisis. So this explanation is highly questionable.

The temporary pain reducing effects often seen with painful treatments, such as dry needling, can be attributed to other well-known neurophysiological processes, such as diffuse noxious inhibitory control, and other non-specific psychological effects, for example, the patient's expectations and placebo effects. ${ }^{7}$ It is also worth remembering that pain is a complex phenomenon. Just because pain is palpated at a location does not mean that this location is the source of pain, and when a treatment is delivered to a structure and it relieves pain, this still does not mean this structure was the source of pain.

\section{SO WHAT ARE WE PALPATING THEN?}

The phenomenon of pareidolia can, I believe, explain what therapists are 'feeling' when they palpate for trigger points. Pareidolia is defined as vague and obscure stimulus that is perceived as something clear and distinct. For example, a therapist's belief or expectation that they will find a trigger point can and does cause them to palpate perfectly normal anatomy and interpret it as an abnormal trigger point. Pareidolia is actually a common phenomenon throughout the musculoskeletal professions and occurs due to multiple factors, such as past experiences, personal preferences and preconceptions. ${ }^{8}$

In summary, alternate theories of what trigger points are do exist. They explain why we often see patients with soft tissue pain that is painful on palpation, but not why we cannot reliably or accurately feel knots or taut bands. However, it must be recognised that these alternative theories also lack any robust evidence and many questions remain still unanswered. In light of this uncertainty, I suggest that we should not be explaining trigger points as muscle knots, but rather that they are simply soft tissue sore spots of an unknown origin!

Twitter Follow Adam Meakins at @adammeakins

Competing interests None.

Patient consent Obtained.

Provenance and peer review Not commissioned; externally peer reviewed.

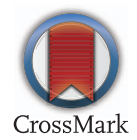

To cite Meakins A. Br J Sports Med 2015;49:348. Accepted 28 January 2015

Br J Sports Med 2015;49:348.

doi:10.1136/bjsports-2014-094502

\section{REFERENCES}

1 Quintner JL, Bove GM, Cohen ML. A critical evaluation of the trigger point phenomenon. Rheumatology 2014:pii: keu471. Published Online First.

2 Quintner JL, Cohen ML. Referred pain of peripheral nerve origin: an alternative to the "myofascial pain" construct. Clin J Pain 1994;10:243-51.

3 Wolfe F, Simons DG, Fricton J, et al. The fibromyalgia and myofascial pain syndromes: a preliminary study of tender points and trigger points in persons with fibromyalgia, myofascial pain syndrome and no disease. J Rheumatol 1992;19:944-51.

4 Chen Q, Bensamoun S, Basford JR, et al. Identification and quantification of myofascial taut bands with magnetic resonance elastography. Arch Phys Med Rehabil 2007;88:1658-61.

5 Shah J, Danoff J, Desai M, et al. Biochemicals associated with pain and inflammation are elevated in sites near to and remote from active myofascial trigger points. Arch Phys Med Rehabil 2008;89:16-23.

6 Simons DG, Hong CZ, Simons LS. Endplate potentials are common to midfiber myofacial trigger points. $A m$ J Phys Med Rehabil 2002;81:212-22.

7 Sprenger C, Bingel U, Büchel C. Treating pain with pain: supraspinal mechanisms of endogenous analgesia elicited by heterotopic noxious conditioning stimulation. Pain 2011;152:428-39.

8 Foye P, Abdelshahed D, Patel S. Musculoskeletal pareidolia in medical education. Clin Teach 2014;11:251-3. 
Meakins A. Soft tissue sore spots of an unknown origin $(\mathrm{Br} J$ Sports Med 2015;49:348). Adam Meakins was incorrectly titled as Dr in the correspondence address of his paper.

Br J Sports Med 2015;49:1026.

doi:10.1136/bjsports-2014-094502corr1

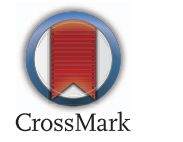

